\title{
A Relationship between Narratology and Marketing
}

\author{
Akinori Abe \\ Faculty of Letters, Chiba University, 1-33 Yayoi-cho, Inage-ku, \\ Chiba 263-8522, Japan
}

\begin{abstract}
We have been studying an expression of the taste of Japanese sake. Actually, the descriptions of the taste can be regarded as stories. Accordingly, we conducted an experiment, in which we asked participants to draw descriptions of the taste of the Japanese sakes and to design labels of them. From the results of the experiment, we will analyse the relationship between narratology and marketing of Japanese sake.
\end{abstract}

Keywords: Narratology, Taste of sake, Marketing.

\section{Introduction}

We have been studying an expression of the taste of Japanese sake (alcoholic drink) ${ }^{1,2,3,4}$. Since we do not have a dictionary of the taste of Japanese sake, we tried to create words or phrases for the taste of Japanese sake. Generally we do not describe the taste of sake as a still situation, but as a changing situation. During describing the taste, we will deal with time. We will describe a gradual change of the taste. Thus the descriptions of the taste can be regarded as stories. The descriptions are interesting as a set of corpus. However more interesting matter is that we may use the descriptions for the marketing. Since the descriptions are generated from the taste of sake, it should contain the taste. And if labels are designed based on the description, it should contain the information of the taste.

Usually labels of the Japanese sake are not attractive. At least, what labels should inform us are name of the sake. No attractive matter is necessary for selling the sake. However, according to the Jensen's theory ${ }^{5}$, it is important to prepare a story for selling products. Accordingly we think it will better to include a story in the labels of sakes. At least labels of sakes should be attractive for a certain generation.

Therefore, we conducted an experiment, in which we asked participants to draw descriptions of the taste of the Japanese sakes and to design labels of them. The design should include the taste information of the sake.
We could collect several results. From the results of the experiment, we will analyse the relationship between narratology and marketing of Japanese sake.

\section{Description of Sake as a Story}

\subsection{Descriptions of the taste of sake}

In several books, we can find the descriptions of taste of sake. For instance, for the taste of Japanese sake, in "LOVE $\odot$ Japanese sake!, 2014, 2 Gakken," we can find the following descriptions:

- Kamoshi-bito Kuheiji (醸し人九平次) Eau Du Desir 2012

At the first moment in the mouth, strong fruit flavour can be felt. After a proper maturing time, the mouth is fragrant with the smell of honey and vanilla. A good flavour is spread and in the center of it splendid sour can be found... (口にした瞬間は果実のフレー バーが強く感じるものの、適度な熟成を経ると 蜂蜜やバニラの香を覚えます。旨味は華やかな 酸を軸に広がりますが....)

- Isojiman Junmai ginjou (磯自慢純米吟醸)

Refreshing scent such as the scent of muskmelon and pear is elegant... (マスクメロンや洋ナシを思わせ る爽快とした香りは気品すら感じさせるも の....)

The above descriptions do not include stories. Perhaps, for the evaluation, subjective descriptions will not be

(C) The 2021 International Conference on Artificial Life and Robotics (ICAROB2021), January 21 to 24, 2021 
preferable. On the other hands, descriptions in several book contain the stories of production such as "Mr. Fernandez who was 79 years old had spent all his life for the wine production (El Vinclo 2010 by Real Wine Guide Vol. 52 (2016, Winter))" and "This taste was born by the malted rice which the president Kimizuka in the winter puts his heart and soul into producing and the fermentation technique that pulls out the potential taste of Fusakogane (an eating rice only in Chiba prefecture) at the best (Naruka special junmai direct packing raw [white] (鳴海特別純米直詰め生【白】) the homepage of Nishiura liquors shop (酒舗にしうら)).”

Previously, we described the taste of Japanese sake ${ }^{1}$. I will show one of the descriptions; The followings are records of two person's expressions for the taste of Japanese sake. We tasted the same sake (Shizengou seven (自然郷 セブン)) at the same time in the same room. We used different cup but the environmental condition will be almost the same.

- A: The first impression in my mouth was oh good taste. However, after that the taste disappeared as if water escaped from the side of the tongue. The first taste of sake did not spread and taste like water went through tongue then escape from my mouth between teeth. Very "interesting" taste.

- F: The first half of tongue can feel good taste. I felt oh good taste. However gradually the taste disappeared as if the taste was veiled in mist. At the last, I had an aftertaste such that sugar is diluted in water. I felt quite a few satisfaction. If I dare to describe the last half taste as a refreshing taste, it can be described that the taste is tightened.

In fact, we used the phrases for the flow of time. Though they do not contain the story of the producer nor process of production, the flow of time during the tasting can be regarded as a story.

\subsection{A label of sake}

Certain labels of Japanese sake contains certain illustrations. “The Japanese sake stories (日本酒ものが たり)” (http://sakemono.com/) by the Japanese sake $\times$ produce production project (日本酒 $\times$ 作家創作プロジ エクト) is conducted as an intention to draw a story in the Japanese sake by artists. For instance, the illustration on the label of Hanahimesakura Shizuku-hime nonfiltered junmai ginjou no-water-added sake (華姫桜 し ずく媛 無濾過純米吟醸原酒) is shown in Figure 1. This is an anime-like illustration.

Though this sake is a non-filtered junmai ginjou nowater-added sake, its taste was fully matured opposite to

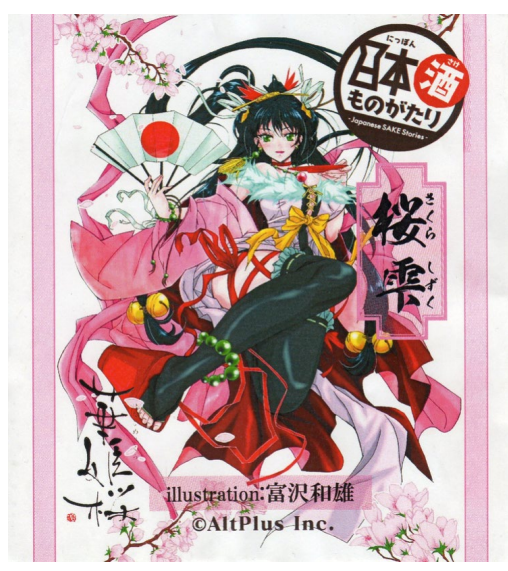

Fig. 1. A label of Japanese sake (華姫桜しずく媛無濾過純 米吟醸原酒)

our expectation. According to the home page, her name is Sakurashizuku (桜需) and she is 138 years old. Accordingly the sake might be matured sake. However, I do not think actual taste of the sake is coincide with the lady in the illustration. At least, the taste is not the similar to what I expected when I saw the label. This illustration might represent the image of the sake as the sake brewery imaged, but does not represent the taste of the sake. If they want to sell this sake to those like idols, it might be successful. Because the illustration contains the story which will be liked by idol lovers. This label includes a story with this lady. We would like to buy the sake with regard to the story read in this label. Thus a story in the product will play an important role in marketing.

\section{Experiment}

We conducted an experiment as follows;

\subsection{Objectives}

Sub-headings should be typeset in boldface italic and capitalize the first letter of the first word only. Section number to be in boldface Roman. We reviewed the role of narratology in the previous section. We concluded in the previous section that a story in the product will play an important role in marketing. Accordingly, we would like to see how can we generate stories from the product and how can we express the stories for the marketing.

\subsection{Participants}

Seven persons from 21 to 29 years old took part in the experiments. Some of them frequently drink Japanese sakes and describe the taste of them. 


\subsection{Method}

We used the following six kinds of sakes: Ichijima junmai ginjou raw no-water-added sake (市島 純米吟醸 生原酒), Azumaichi junmai daiginjou (東一 純米大吟 醸 ), Azumaichi Yamadanishiki junmai-shu 64l\% polishing (東一山田錦純米酒 641\%磨き), Azumaichi Nero, Azumaichi junmai daiginjou drip squeezing (東一 純米大吟醸 需搾り), Inabazuru junmai ginjou gouriki freshly squeezed non-filtered raw no-water-added sake
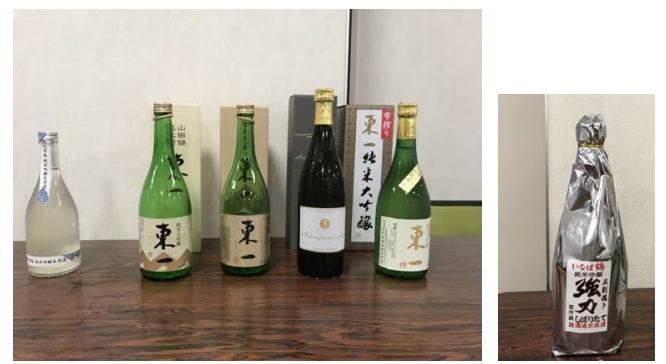

Fig. 2. Japanese sakes used in this experiment

\section{(いなば鶴 純米吟醸 強力しぼりたて 無濾過生原酒)}

We asked the participants to taste Japanese sake to describe the taste. The description could include texts and figures. Then we asked them to create catch copies for the sake. In addition, we asked them to design the label of the sake. The target person was young person in 20's. Those descriptions and drawings were drawn on the papers in A3 size. They used several pens such as coloured pens and pencils.

\subsection{Results}

We collected such results as shown in Figure 3.

First, we show some descriptions of the taste of sake. All descriptions were written in Japanese. We translated them in English.

- Ichijima junmai ginjou raw no-water-added sake

1) Delicious. I like this because I can smell and taste rice. Since it contains spicy taste, the taste comes gradually. At first, I feel gentle taste, but in latter half I feel spicy taste.

2) Jyowa jyowa--- The fragrance disappears suddenly and clearly. A refreshing fragrance which is going out from nose. For the summer season? I can not say it is a refreshing type. With snack it is not good. With a Camembert cheese, the taste becomes soft. For a party? It is difficult to drink without any foods.

3) (fragrance) I like the fragrance.

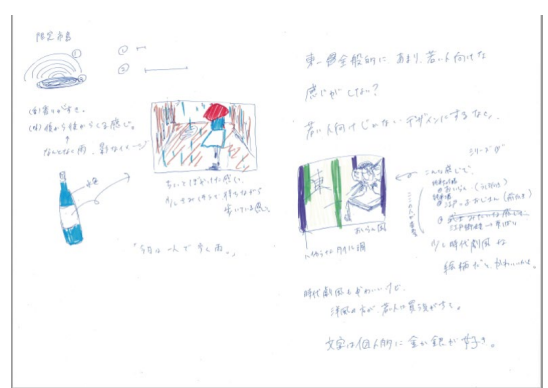

Fig. 3. One of results in this experiment

(taste) The taste comes again and again. I feel somewhat an image of rain and shadow.
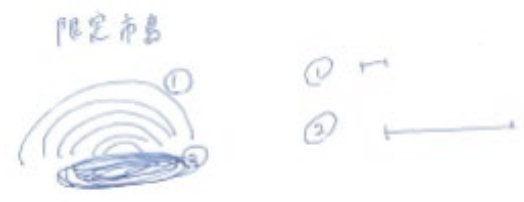

4) (fragrance) I feel a straight alcoholic fragrance.

(taste) Strong sour and slightly sweet. After taste includes spicy. Bitter taste is weak.

5) Spicy banana

mine) I feel fragrance of cloth. First sweet taste such as pears comes to mouth and spread slightly. Unfavourable taste flows out of mouth but it is not hate taste. With a duck, I can taste without conflictions. Smoked taste becomes weak.

- Azumaichi junmai daiginjou

1) I feel sweet and floral feeling. When I open the sake, I feel a fragrance from the $20 \mathrm{~cm}$ distance, the taste is soft and I feel umami of rice. The more I drink, I become aware of biting taste. If I drink a lot, spreads of the sake will change? It is easy to drink, so I can drink more and more. I think I can get drunk comfortably. It will be good for drinking when tired? But it is not good to drink before holiday. I might not be aware of having a hangover.

2) Refreshing fragrance. The first attack is pliant sweet. It is rather bitter. The balance of the taste is good. After a while, I feel a bitter taste more. The target generation of the sake will be elder persons. Younger generation will not like this. The taste is bitter, but after taste does not remain long. So it will be good for with a meal. After a long time, the taste changes flat and I do not feel a bitter taste. 
3) (fragrance) Fresh and young type. (taste) strong sour. At (1), a prickly taste comes and at (2) also a prickly taste comes. Then the taste spread to (3) rapidly. The taste remains more at (1) and (2) than at (3). It has a peculiar taste but is easy to drink. It is a feminine type sake.

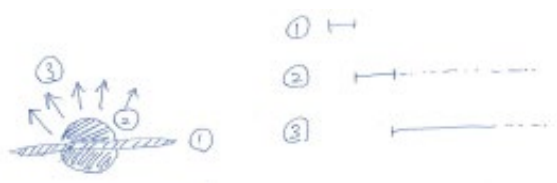

4) (fragrance) Sweet fragrance of rice which comes my nose straightly and a straight alcoholic fragrance.

(taste) First, I feel a sweetness of rice. The taste becomes bitter as the sake enters the back of tongue. At the throat I feel a biting taste. It is easy to drink (because a bitter taste dose not come suddenly). After taste is sweetness of a rice and I feel a biting taste in the throat. At the back of throat, I feel a little bitter taste.

mine) Fragrance like a dust. A taste like a fruit (apple) comes in the shape of round and thickly. The taste does not spread and comes heavily. However, At the top of the tongue, spicy taste. In the mouth, a remaining taste is faintly sweet and clear. If it does not have spicy taste, it is clear taste.

- Azumaichi Yamadanishiki junmai-shu 64\% polishing 1) A sharp feeling. Cool. Good for summer. Cool feeling $\rightarrow$ I cannot feel the fragrance. The taste is sour? like a caramel. I feel bitterness rather than sweetness. But sweet. It's difficult to deal with expressing the taste. The taste spreads a little. The taste stops at the place where I feel like to go more. It the type of sake that tantalizes after appealing to me. It is like a quiet and cool pretty girl such as Rei Ayamaru (綾○レイ).

2) It is a normally delicious sake. It is neither good nor bad. It is better than Ichjima and Azumaichi Junmai daiginjou. If I do not have any sake, I will drink. I can drink with every foods.

3) (fragrance) astringent. (taste) A prickly taste comes and spreads with numbing. After drinking the sake, at (2) and (4) the taste remains. In addition, at (5), the taste remains. The taste is like a little bitter chocolate remains in the mouth (A cacao degree is high.). The taste in (3) moves back and forth according to the way of putting it in my mouth. The taste in (3) spreads overall slowly. The after taste is a chocolate.

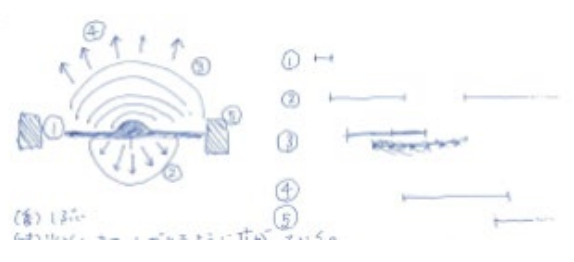

4)(fragrance) Rather strong fragrance.

(taste) Just after putting the sake in my tongue, I feel a spicy taste. I feel sweetness little and the after taste has a bitterness. But the taste is more refreshing than that of Azumaichi junmai ginjou. I feel a spicy taste at the top of my tongue.

5) Middle: clear, a clear stream, acid, forest, summer, late summer, September, sun light through the trees Later: Autumn rice field with swaying inaho, refreshed taste. A fine autumn day. A rim of the taste is clear.

mine) A little fragrance of an alcohol exists bottom of the sake. The taste is matured and at the bottom of the sake, an alcoholic taste sinks. At the upper side of the sake exists thin sweetness. I feel a spicy taste at the top of my tongue. I feel an astringency spreading around my cheek.

- Azumaichi Nero

1) Its taste is similar to that of Azumaichi junmai daiginjou? If it is said as sweets, it will belong to the sweets. The taste is rather sweet and it comes gradually. The taste is not spreading wider than that of Azumaichi junmai daiginjou. I feel like a drinking sake more than Azumaichi junmai daiginjou drip squeezing.

2) I can smell nothing. Its taste is calm and gentle. I feel carbonic acid. I think it is better to drink with yakitori. Perhaps with sashimi. After a little while, it becomes melting. And more time after, it becomes sticky.

3) (taste) Its taste is strong. (4) remains ..., but is rather smooth. At the last, taste is clean.
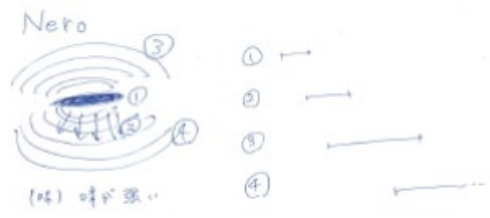

4) (fragrance) I feel a straight fragrance. No sweet fragrance I feel.

(taste) The taste of sweetness of a rice and sour strongly comes. The after taste is slightly (gentle) spicy and bitter. 
mine) I feel a closed fragrance. A fruit type of taste comes smoothly. It spreads very little and on my tongue sweetness remains. I feel little unfavourable taste. If I inflate the sake in my mouth, a little sour comes and the taste of the sake becomes very well balanced. At the last, I feel a spicy taste on my tongue, but I mind a little.

- Azumaichi junmai daiginjou drip squeezing 1) The spreading of the taste is a little. I have a unremarkable impression. Spicy? I feel a prickly taste. I think I can recommend to everybody?

2) I feel a rich fragrance. This is a hoping sake. The taste is not bad. I will drink later. A cheap taste. I can dare to drink it in a train alone. For a party. After several minutes, a bitter taste comes a little.

$3)$ (fragrance) I smell a little. pretty.

(taste) like a melon. pretty. At (3) the taste comes with a heavy impact. "It is not just a pretty face." I feel it is like a pearl.

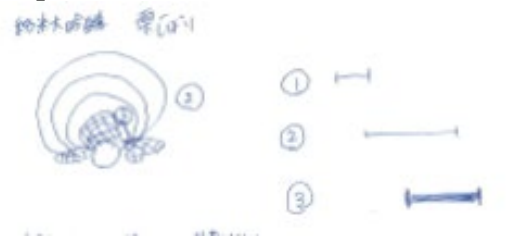

4) (fragrance) Fragrance of sweetness of rice and alcohol.

(taste) I feel a taste of strong flavour of a rice. In addition, I feel sweetness and slightly acidity. On the throat, I feel relatively strong spicy taste. Even if I drink it with air, a spicy taste comes.

5) Mowa--n, unformel, it has an outline.

mine) I smell fragrance of cloth a little. On the periphery, clear sweetness exists. The taste enters in mouth cleanly. I feel a spicy taste over the sweetness. Its clear sweetness is like a delicious water and beautiful. However, I want a more spreading taste. Without the last spicy taste, it will become a nonstimulative sake? It it had umami or rich flavor, it will be the best.

- Inabazuru junmai ginjou gouriki freshly squeezed non-filtered raw no-water-added sake

2) I drink it with sweets. The taste is not bad. (It might because I drink it with sweets.) It smells like fruits (green apple). mine) At first, the taste is closed. A sour taste stands out, but is not strong. It is easy to drink, but does not have a special feature.

Next, we show some catch copies for sakes.

- Ichijima junmai ginjou raw no-water-added sake

2) Best for the summer party... with cheese and ham.

3) It's raining... today I walk alone.

4) Spreading taste.

5) If we get drunk, everything is tasteful.

- Azumaichi junmai daiginjou

2) For the sake lovers!! The best in Azumaichi.

3) Scared 怖い lady (gentle lady)

4) Seven changes

5) Flower blooms four times.

- Azumaichi Yamadanishiki junmai-shu 64\\% polishing

1) A friend with an evening drink.

2) The entry item of Azumaichi!!

3) The first step to adult.

- Azumaichi Nero

2) It's very clear taste. So you can taste it with both meats and fishes.

5) 25 years old, week end, girls party.

- Azumaichi junmai daiginjou drip squeezing

2) Please taste slowly.

4) Happiness of a drop.

5) Metamon transforms Japanese sake. Drinking rice ball sake.

Several catch copies were collected. These copies are for younger generation. An interesting copy is that for Azumaichi junmai daiginjou. It might have changing taste, accordingly they generate phrases with words meaning change.

Then according to the catch copies, participants created labels for the sakes as shown below:

- Ichijima junmai ginjou raw no-water-added sake

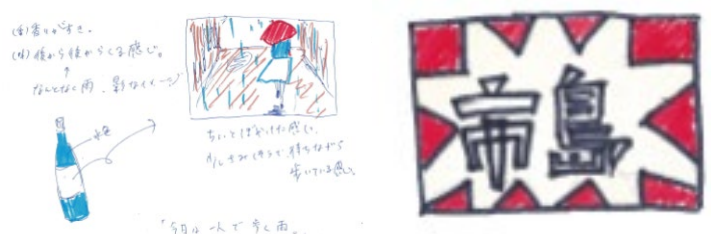

- Azumaichi junmai daiginjou 

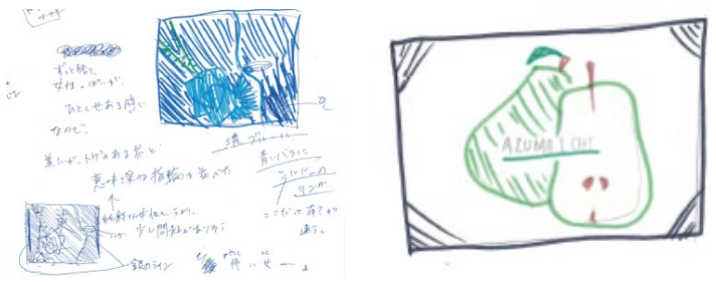

- Azumaichi Yamadanishiki junmai-shu 64\\% polishing

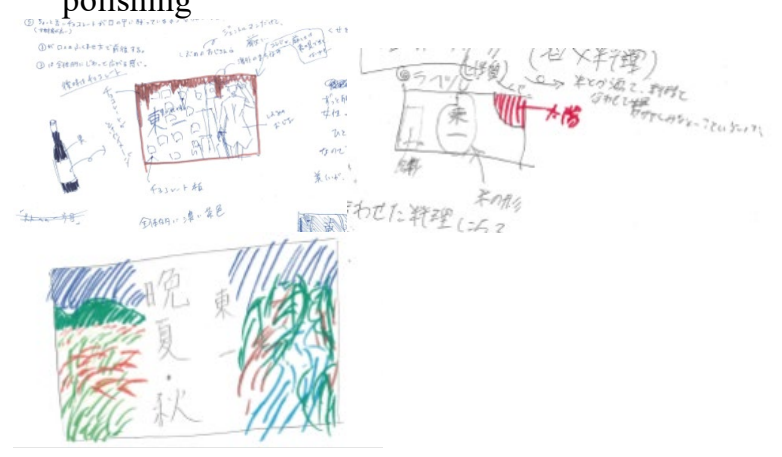

- Azumaichi Nero

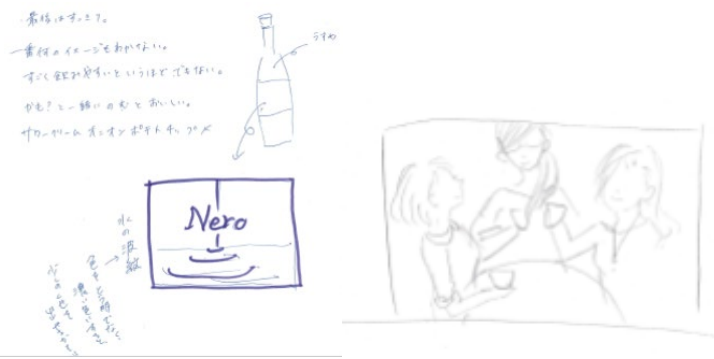

- Azumaichi junmai daiginjou drip squeezing
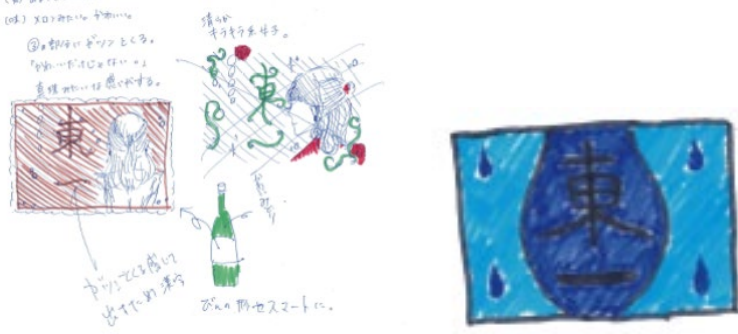

Some labels have stories.

\section{Discussions}

In the experiment, we collected several results. They are descriptions of the taste of the sake, catch copies for the selling the sakes, and labels of sakes. We expected stories in the descriptions of the taste. Some participants described changing tastes. We think these are stories for the sakes.
A sommeliere sometimes describes a taste of a wine with a scene such as "walking in a forest with stepping firmly dead leaves." This expression comes from the changing taste. We think for the description of the taste of Japanese sake, this type of expression can be made.

Reviewing the labels, we think a story of the taste is described in certain label. And the story (narratology) functions well in the labels. We think illustration in the label expresses the story of the taste of the Japanese sake. We think it will be better to express the story of the taste of the sake. It has a lot of information to select a product.

We did not conduct an experiment to evaluate the design of labels by somebody. This is a unsolved question for the future.

\section{Conclusions}

In this paper, we conducted series of experiments. First, we asked the participants to taste Japanese sake to describe the taste. The description could include texts and figures. Then we asked them to create catch copies of the sake. In addition, we asked them to design the label of the sake.

We could collect several expressions from this experiment. The expressions are very interesting. The more interesting results are labels designed by the participants. We think some labels can be used for the marketing.

We have not evaluate the designs. In the future, it is necessary to evaluate them by outsiders.

\section{Acknowledgements}

We thank Mr. Ippei Setou for offering us Japanese sakes (Azumaichi).

\section{References}

1. Akinori Abe: About the better expression of taste, Proc.of the 2nd. Int'l Workshop on Language Sense on Computer in IJCAI2017, pp. 28-34 (2017)

2. Akinori Abe: Is the expression of taste abstract or representational?, Proc. of SMC2018 Workshop on Narratology and Cognitive Content Generation, pp. 18-23 (2018)

3. Akinori Abe: Expression of the taste of Japanese sake and metaphor, Proc. of ICAROB2019, pp. 589-592 (2019)

4. Akinori Abe: Taste of Japanese Sake as Metaphor and Shape, Proc. of IJCAI2019 The 3rd. International Workshop on Language Sense on Computer, pp.29-34 (2019)

5. Rolf Jensen: The Dream Society: How the Coming Shift from Information to Imagination Will Transform Your Business, Mcgraw Hill (1999) 